\title{
GCU
}

Glasgow Caledonian

University

University for the Common Good

\section{Clustering of lifetime substance use and sexual intercourse among young people: analysis of two school-based surveys}

McAloney-Kocaman, Kareena; Rogon, Paul J.S.; Ireland, Lana

Published in:

Journal of Child and Adolescent Substance Abuse

DOI:

10.1080/1067828X.2019.1602090

Publication date:

2019

Document Version

Author accepted manuscript

Link to publication in ResearchOnline

Citation for published version (Harvard):

McAloney-Kocaman, K, Rogon, PJS \& Ireland, L 2019, 'Clustering of lifetime substance use and sexual intercourse among young people: analysis of two school-based surveys', Journal of Child and Adolescent Substance Abuse, vol. 28, no. 2, pp. 99-104. https://doi.org/10.1080/1067828X.2019.1602090

\section{General rights}

Copyright and moral rights for the publications made accessible in the public portal are retained by the authors and/or other copyright owners and it is a condition of accessing publications that users recognise and abide by the legal requirements associated with these rights.

Take down policy

If you believe that this document breaches copyright please view our takedown policy at https://edshare.gcu.ac.uk/id/eprint/5179 for details of how to contact us. 
Clustering of lifetime substance use and sexual intercourse among young people: analysis of two school-based surveys.

Kareena McAloney-Kocaman ${ }^{a}$, Paul J.S.Rogon ${ }^{b}$ and Lana Ireland ${ }^{a}$

aDepartment of Psychology, Social Work and Allied Health Sciences, Glasgow Caledonian University, Cowcaddens Road, Glasgow, G4 0BA.

${ }^{\text {bS }}$ cottish Children's Reporter Administration (SCRA), Ochil House, Springkerse Business Park, Stirling, FK7 7XE

Corresponding author: Dr Kareena McAloney-Kocaman, Department of Psychology, Social Work and Allied Health Sciences, Glasgow Caledonian University'

Cowcaddens Road, Glasgow, G4 0BA. Telephone: 0141331 8451;

Email:Kareena.mcaloney@gcu.ac.uk 


\section{Abstract}

Adolescents commonly engage in substance use and sexual behaviours which pose risks for their health. Secondary data analysis of two school based surveys explored the clustering of lifetime use of cigarettes, alcohol, cannabis, and engagement in sexual intercourse among 2489 adolescents in Scotland and 1405 adolescents in Northern Ireland. All four behaviours were clustered with substantially higher prevalence than expected (11 and 24 times higher respectively). Multiple logistic regression models indicated associations of the four behaviour cluster with sociodemographic factors, with family structure operating as a predictor of clustering across the sample, and deprivation operating as a predictor for the Scottish sample. This suggests a need to focus on the interdependence of risk behaviours and factors associated with engagement in risk clusters in distinct cultural settings.

Keywords - clustering, substance use, adolescents Funding: No funding source

Disclosure statement: No funding source. The authors declare no conflict of interest 
Adolescence (between 10 and 19 years old) is a time when many young people engage in behaviours typically considered to be risky, such as substance use and sexual activity, which can have negative consequences for health and well-being (WHO, 2018). Smoking cigarettes, consuming alcohol, and using cannabis are among the most prevalent substance use behaviours in the adult population (Gowing et al., 2015). These three substance use behaviours tend to have high rates of experimentation in adolescence, resulting, frequently, in initiation into a sustained pattern of use beyond adolescence and across the life span (van Nieuwenhuijzen et al., 2009).

Cigarettes and alcohol both pose considerable health risks, tobacco consumption accounts for around $11 \%$ of deaths among men, and $6 \%$ of deaths among women globally (Gowing et al., 2015), while alcohol accounts for approximately $5.9 \%$ of deaths globally (WHO, 2014). Cannabis use has been consistently linked with a spectrum of physical and mental health issues (Hall \& Degenhardt, 2009). Similarly although sexual activity is developmentally normal, there is substantial evidence to indicate that sexually active adolescents have disproportionately higher levels of engagement in unprotected sex, activity with multiple partners, sexually-transmitted infections (STIs) and pregnancy (Edelman, de Visser, Mercer, McCabe \& Cassell, 2015).

Not all young people will engage in these substance use and sexual behaviours, but among those who do there is evidence that they will engage in more than one of these, in a cluster-like fashion. Cigarette use has consistently been linked with use of other substances (Conway et al., 2018; Ramo, Liu \& Prochaska, 2012; Richter, Pugh, Smith \& Ball, 2017), as well as with sexual risk behaviours (McAloney, McCrystal \& Percy, 2010; Ritchwood, DeCoster, Metzger, Bolland and Danielson, 
2016). Adverse sexual outcomes and risk behaviours have been linked with a range of substance use behaviours, including smoking, alcohol consumption and cannabis use (Edelman et al., 2015; Young, Burke \& Nic Gabhainn, 2018). Research associations between adolescent smoking and 'early sexual initiation' have been found for females in particular, with Jackson, Sweeting and Haw (2011) finding clustering effects related to gender but not social class. Ritchwood, Ford, DeCoster, Sutton and Lochman (2015), however, reported a weak to moderate relationship between risky sexual behaviours and substance use in adolescents in their metaanalysis, indicating that the strength of the effect varied by type of sexual activity, and was moderated by socio-demographic variables.

While several studies have investigated the co-occurrence of risk behaviours in adolescence, increasingly those investigations have been extended to examine the clustering, or statistical interdependence, of the behaviours (McAloney Graham, Law \& Platt, 2013). In their systematic review Meader et al. (2016) reported that among young adults sexual risk behaviours and substance use are consistently clustered, although they suggest a need for further research on the clustering of cigarette use with sexual risk behaviours. Variations in clustering and co-occurrence of risk behaviours have been reported across socio-demographic characteristics (de Winter, Visser, Verhulst, Vollebergh \& Reineveld, 2016; McAloney, 2015), and Meader et al. (2016) identified socio-economic status as the most influential predictor of engaging in clustered risk behaviours.

Participation in more than one of the behaviours presents an increased potential for negative health consequences as a result, and consequently it is important to understand the patterns of risky behaviours that young people engage with. This paper aimed to investigate clustering of lifetime/ever cigarette smoking, alcohol 
consumption, cannabis use and sexual intercourse among adolescents, using data from two large school-based surveys, and to explore socio-demographic factors associated with lifetime engagement in all four behaviours.

\section{Method}

\section{Participants}

The samples consisted of 2489 young people ages 14 - 17 years who completed the Health Behaviours in School Aged Children Scotland Survey 2014 sweep (HBSC; Inchley, 2017); and 1405 young people aged 14 - 18 years who completed the Northern Ireland Young Persons' Behaviour and Attitudes Survey 2013 (YPBA; Northern Ireland Statistics and Research Agency Central Survey Unit, 2015), and had responses on the four behaviours of interest. The HBSC Scotland study is part of a large-scale, international, school-based study including data from young people across 44 countries and regions, addressing health and well-being. The YPBA is a school-based survey of young people in Northern Ireland. Both surveys are provided with weighing variables to account for the study designs and non-response.

The gender distribution across both samples was fairly even (HBSC male = $49.2 \%_{\text {weighted }}$ Y YPBA male $\left.=50.6 \%_{\text {weighted }}\right)$. The weighted mean age of the HBSAC sample was 15.67 years $\left(s d_{\text {unweighted }}=0.38\right)$, and for the YPBA was 15.37 years $\left(s d_{\text {weighted }}=0.64\right)$

\section{Measures}

The design and scope of both surveys are reported elsewhere (Currie, Inchley, Molcho, Lanzi, Veselska \& Wil, 2014; Northern Ireland Statistics and Research Agency Central Survey Unit, nd). Both surveys are school based surveys of adolescents, weighted for representativeness. Participants are asked to self-report 
on measures across a number of domains related to their health, well-being, behaviours, family, environment and experiences. For this study only the variables of interest are detailed below.

Substance use behaviours. In the HBSC survey participants were asked to indicate how often in their lifetime they had consumed each of three substances - cigarettes, alcohol and cannabis. In the YPBA participants were asked to indicate if they had ever used any of the three substances. Responses where dichotomised to a yes/no response for ever use of the substance in order to harmonise the outcome variables across the two surveys to allow the same analysis to be performed across both surveys.

Sexual intercourse. In the HBSC survey participants were asked to indicate if they had ever engaged in sexual intercourse. In the YPBA participants were asked to indicate how much sexual experience they had, with a response option to record if they had participated in sexual intercourse. All responses where dichotomised to a yes/no response for ever had sexual intercourse, again to allow the same analysis to be performed across both surveys.

Socio-demographics. All participants were asked to indicate their gender and their age. For the YPBA age was recorded rounded to the nearest whole year, while for the HBSC age was recorded as years and months relative to the date of data collection. Deprivation was included as a reflection of socio-economic status. It was recorded in both surveys as an index of Multiple Deprivation (Scottish Index of Multiple Deprivation; and NI Index of Multiple Deprivation), participants were recorded in one of 5 deprivation groups based on established quintile thresholds (1 most deprived; 5 - least deprived). Both indexes reflect relative deprivation based on 
indicators across domains of income, health, employment, education, housing and crime at a geographical area level. The HSBC data file contained a derived variable of family structure, with options of both parents, single parent, step-parent, and other. The YPBA contained several items recording who the young person lived with, which were used to create a family structure variable with the same codes as the HSBC variable. Responses which indicated kinship care and foster care were coded as other.

\section{Procedure}

Frequencies of participation in each of the four risk behaviours were produced for both samples, and clustering was investigated with the Odds/Expected $(\mathrm{O} / \mathrm{E})$ ratio method (Hardy et al., 2012). Using this method the prevalence of each individual behaviour within the sample is calculated, expected prevalence figures for the specific behaviour combinations are then derived by multiplying the individual prevalence values each divided by 100 , together and multiplying this figure then by 100 to reflect the proportion of the sample that would be expected to display that particular combination if the behaviours were independent. For example for the behaviour combination of smoking, alcohol, no cannabis use and no sex the calculation would be: ((prevalence of smoking/100)*(prevalence of alcohol $/ 100)^{*}($ prevalence of none use of cannabis/100)*(prevalence of no sexual intercourse/100))*100. Behaviours are clustered when the observed frequency of the specific combination differs from the frequency expected for co-occurring but independent behaviours. O/E ratios greater than 1.00 indicate higher than expected prevalence, and therefore interdependence of the behaviours, while values less than 1.00 indicate a lower than expected prevalence. 95\% confidence intervals are produced to reflect the confidence in the O/E value and to indicate where 
interdependence is present. Multiple logistic regression models were estimated to investigate associations between socio-demographic factors and participation in all four behaviours. Descriptive analyses, and multiple logistic regressions were performed in SPSS 23.0, and calculations of the O/E ratio performed in Excel.

\section{Results}

As can be seen in table 1 for both samples having consumed alcohol was the most frequently reported behaviour, followed by having smoked a cigarette. Of particular note the prevalence of each behaviour were considerably higher for the Scotland sample than the Northern Ireland sample, and with the exception of cigarette smoking the differences in prevalence where statistically significant. While cannabis and sexual intercourse had comparable prevalence rates among the Northern Ireland youth at around 10\%, one quarter of the Scotland sample had engaged in sexual intercourse, and over one sixth had consumed cannabis.

\section{[Table 1]}

The proportion of young people in Scotland reporting all four behaviours was three times greater than in Northern Ireland (table 2), while just over one fifth of the young people in Scotland reported none of the behaviours compared to almost two fifths of young people in Northern Ireland. Among the Scotland sample prevalence rates of participation in a single, two, three and all four behaviours were higher than among the Northern Ireland sample.

[Table 2]

Table 3 displays the observed frequencies and the O/E ratios for both samples. Most behaviour combinations were less prevalent than expected if the behaviours were 
independent, and a number of combinations were more prevalent; indicating clustering of the four behaviours. In both the Scotland and Northern Ireland samples participation in none of the four behaviours was more common than expected, with prevalence two times higher for the Scotland sample and one and a half times higher in the Northern Ireland sample. Similarly the prevalence of the combination of cigarettes, alcohol and cannabis was two times greater in the Scotland sample, and four times greater in the Northern Ireland sample than expected. For the Scotland sample the use of alcohol, without lifetime use of any other substance or engagement in sex was also slightly more prevalent than expected. In both the Scotland and Northern Ireland samples lifetime participation in all four behaviours was also clustered. Lifetime participation in all four behaviours was 11 times higher than expected in the Scotland sample, and 24 times higher than expected in the Northern Ireland sample.

Notably, none of the participants in either sample reported lifetime use of cigarettes and sexual intercourse, in the absence of alcohol and cannabis. For the Northern Ireland sample there were also no reports of lifetime cannabis use only, lifetime cannabis use and sexual intercourse, or lifetime use of cigarettes, cannabis, and sexual intercourse.

[Table 3]

Logistic regression models were estimated to explore socio-demographic factors associated with membership of the four behaviour cluster (table 4). For young people from Northern Ireland the odds of lifetime participation in all four increased with age, and young people from single parent families had odds two times greater compared to those where both parents were present. For young people to Scotland a slightly 
different pattern emerged. Age was not significantly associated with the four behaviour cluster, however both family structure and deprivation were. Young people from single parent families, and families with a step-parent present had greater odds compared with those where both parents were present. Those young people in the highest, and second highest deprivation groups had almost three times higher odds of lifetime participation in all four behaviours compared to those in the lowest deprivation group.

\section{Discussion}

In both the Scotland and Northern Ireland samples, the majority of young people engaged in one or more risk behaviours, with a notable proportion engaging in multiple risk behaviours. The results indicate an interdependent relationship between lifetime smoking, alcohol consumption, cannabis use and sexual activity, with these behaviours statistically clustered rather than simple co-occurrence of the behaviours, and lends further support to the claim of shared underlying processes (Jessor, 1991; Weis et al., 2008). While for many of the combinations the prevalence is lower than expected, it is important to note that for both samples the combination of cigarette, alcohol and cannabis use; and of all four behaviours occurs at a much greater prevalence that expected, highlighting a need to recognise and address not just the individual behaviours but the interdependence among them.

Of particular note are the deviations in prevalence across the two samples, where the sample of young people from Scotland had consistently higher prevalence of each of the individual behaviours, number of risk behaviours, and for many of the behaviour clusters. The sample from Northern Ireland did, however, have higher prevalence rates for consumption of cigarettes and alcohol only, for cigarettes only, and for participation in none of the behaviours in comparison with the Scotland 
sample. Individually there were substantially lower rates of lifetime cannabis consumption and of sexual intercourse among the Northern Ireland sample. While an explanation for this discordance in prevalence rates among youth samples from different regions of the UK is beyond the scope of this paper, it may reflect differences at a societal and community level, such as levels of religiosity and religious conservatism which is traditionally higher in Northern Ireland than in Scotland (Mitchell, 2006; Sneddon \& Kremer, 1992) or accessibility of the behaviour. Scotland and Northern Ireland both have large rural areas and populations, however Northern Ireland has restricted public transport systems and access compared to other areas of the UK, and it is possible that this may restrict the ability of young people to engage with these behaviours.

Despite the differences in prevalence rates across both samples family structure emerged as significant factors in participation in all four risk behaviours, with young people from single parent families more likely to engage in all four behaviours, as where young people with step-parents in the Scotland sample. Deprivation did not emerge as a significant predictor for the sample from Northern Ireland which is contrary to the findings of Meader et al. (2016), but was for Scotland, where the odds were between 2.5 and 3 times higher of participation in all four behaviours for deprived youth. Interestingly however, gender was not significantly associated with the 4 risk cluster in the model for either sample, which is contrary to other findings where there were variations across gender groups (McAloney, 2015). This suggests that male and female adolescents may be equally at risk of engagement with these substances and sexual activity, and interventions to reduce engagement should be targeted equally to male and female youth. 
The findings suggest variations in vulnerability to risk behaviours among young people across these two regions of the UK, and indicate an interdependence among the risk behaviours of cigarette use, alcohol consumption, cannabis consumption and sexual intercourse which needs to be better understood in order to appropriate direct resources to support young people as they develop through adolescence. Although experimentation is considered developmentally appropriate at this life stage (Bartlett, Holditch-Davies \& Belyea, 2007), it is important to further explore the factors that influence young peoples' risk behaviours, to ensure that experimentation at this stage does not set in train a pattern of consistent use, and subsequent health problems (Due et al, 2011). Future research may wish to assess qualitatively the experiences and decision-making processes of adolescents around their clustering of substance use and sexual behaviours.

This study does have several limitations which must be recognised, most notably the focus on 'ever' participating in the behaviours, which does not allow for any distinction to be made between experimentation with a substance or activity and initiation of that behaviour over a more sustained period of time. However this dichotomization is necessary to identify if statistical significant clusters of behaviours are present (McAloney et al., 2013). Further research which explores the clustering of established substance use patterns among young people would be beneficial. Additionally there were limitations as to the number of socio-demographic characteristics which could be explored in this analysis, due to the secondary data analysis design and the use of regional data sets. Socio-demographic characteristics included in this analysis were restricted to those which were consistent across both surveys. Both samples were drawn from existing surveys conducted in Northern Ireland and Scotland within school settings, and so may not be representative of 
adolescents in other countries or locales; although both surveys are weighted to support representativeness of their populations.

Despite these limitations the findings indicate a statistical interdependence of these lifetime risk behaviours in young people, and identify a number of socio-demographic characteristics - family structure, age and deprivation, which may make young people more vulnerable to engagement with multiple risk behaviours. More research is needed to understand young people's vulnerabilities to multiple risk behaviours, and how clustering of lifetime risk behaviours is related to consistent engagement in risks.

\section{References}

Bartlett R, Holditch-Davis P and Belyea M (2007).Problem behaviors in adolescence. Pediatric Nursing, 33(1), 13 - 18.

Conway, K.P., Green, V.R., Kasza, K.A., Silveira, M.L., Borek, N., Kimmel, H.L., Sargent, J.D., Stanton, C.A., Lambet, E., Hilmi, N., Reissig, C.J., Jackson, K.J., Tanski, S.E., Maklan, D., Hyland, A.J. \& Compton, W.M. (2018). Co-occurrence of tobacco product use, substance use, and mental health problems among youth: Findings from wave 1 (2013 - 2014) of the population assessment of tobacco and health (PATH) study. Addictive Behaviors, 76, 208 - 217. DOI:

10.1016/j.addbeh.2017.08.009

Currie C., Inchley J., Molcho M., Lenzi M., Veselska Z. \& Wild F. (eds.) (2014). Health behaviour in school-aged children (HBSC) study protocol: background, methodology and mandatory items for the 2013/14 survey. Child and Adolescent 
Health Research Unit (CAHRU), University of St Andrews. Retrieved January 20, 2018 from http://www.hbsc.org/news/index.aspx?ni=2418

de Winter, A.F., Visser, L., Verhulst, F.C., Vollebergh, W.A.M. \& Reijneveld, S.A. (2016). Longitudial patterns and predictors of multiple health risk behaviors among adolescents. Preventive Medicine, 8, 76 - 82.

Due P, Krølner R, Rasmussen M, et al. (2011). Pathways and mechanisms in adolescence contribute to adult health inequalities. Scandinavian Journal of Public Health, 39(6), 62-78.

Edelman, N.L., de Visser, R.O., Mercer, C.H., McCabe, L. \& Cassell, J.A. (2015). Targeting sexual health services in primary care: a systematic review of the psychosocial correlates of adverse sexual health outcomes reported in probability surveys of women of reproductive age. Preventive Medicine, 81, 345 - 356. DOI: 10.1016/j.ypmed.2015.09.019

Gowing, L.R., Ali, R.L., Allsop, S., Marsden, J., Turf, E.E., West, R. Witton, J. (2015). Global statistics on addictive behaviours: 2014 status report. Addiction, 110(6), 904 - 919. DOI: 10.1111/add.12899

Hall, W. \& Degenhardt, L. (2009). Adverse health effects of non-medical cannabis use. The Lancet, 374(9698), 133 - 1391.

Hardy, L. L., Grunseit, A., Khambalia, A., Bell, C., Wolfenden, L., \& Milat, A. J. (2012). Co-occurrence of obesogenic risk factors among adolescents. Journal of adolescent health, 51(3), 265-271. DOI: 10.101'j.jadohealth.2011.12.017 Inchley, J. (2017). Health Behaviour in School-aged Children Study in Scotland, 2014. [data collection]. UK Data Service. SN: 8123, DOI: 10.5255/UKDA-SN-8123-1 
Jackson C, Sweeting H, \& Haw, S. (2011). Clustering of substance use and sexual risk behaviour in adolescence: analysis of two cohort studies. BMJ Open 2012;2:e000661. doi: 10.1136/bmjopen-2011-000661

Jessor, R, Chase, CA and Donovan, JE (1980). Psychosocial correlates of marijuana use and problem drinking in a national sample of adolescents. American Journal of Public Health, 70, $604-613$.

McAloney, K. (2015). Clustering of sex and substance use behaviours in adolescence. Substance Use and Misuse, 50(11), 1406 -1411. DOI: $10.3109 / 10826084.2015 .1014059$

McAloney, K., Graham, H., Law, C. \& Platt, L. (2013). A scoping review of statistical approached to the analysis of multiple health related behaviours. Preventive Medicine, 56(6), 365 - 371. DOI: 10.1016/j.ypmed.2013.03.002

McAloney, K., McCrystal, P. \& Percy, A. (2010). Sex, drugs and STDs: preliminary findings from the Belfast Youth Development Study. Drugs: Education, Prevention and Policy, 17(4), 443 - 453. DOI: 10.3109/09687630903074826

Meader, N., King, K., Moe-Byrne, T., Wright, K., Graham, H., Petticrew, M., Power, C., White, M., \& Snowdon, A.J. (2016). A systematic review on the clustering and cooccurrence of multiple risk behaviours. BMC Public Health, 16, 657- 666. DOI: $10.1186 / s 12889-016-3373-6$

Mitchell, C. (2006). Religion, identity and politics in Northern Ireland. Boundaries of belonging and belief. Aldershot, England: Ashgate Publishing Ltd. 
Northern Ireland Statistics and Research Agency. Central Survey Unit. (2015). Young Persons' Behaviour and Attitudes Survey, 2013. [data collection]. UK Data Service. SN: 7624, DOI: 10.5255/UKDA-SN-7624-1

Northern Ireland Statistics and Research Agency. Central Survey Unit. (nd). Young Persons' Behaviour and Attitudes Survey 2013: Technical Report. Northern Ireland Statistics and Research Agency, Retrieved January 20, 2018 from https://www.nisra.gov.uk/sites/nisra.gov.uk/files/publications/YPBAS2013TechnicalR eport.pdf

Ramo, D.E., Liu, H. \& Prochaska, J.J. (2012). Tobacco and marijuana use among adolescents and young adults: A systematic review of their co-use. Clinical Psychology Review, 32, 105 - 121. DOI: 10.1016/j.cpr.2011.12.002

Richter, L., Pugh, B.S., Smith, P.H. \& Ball, S.A. (2017). The co-occurrence of nicotine and other substance use and addiction among youth and adults in the United States: Implications for research and practice. The American Journal of Drug and Alcohol Abuse, 43, 132 - 145. DOI: 10.1080/00952990.2016.1193511

Ritchwood, T.D., DeCoster, J., Metzger, I.W., Bolland, J.M. \& Danielson, C.K. (2016). Does it really matter which drug you choose? An examination of the influence of type of drug on type of risky sexual behaviour. Addictive Behaviors, 60, 97 - 102. DOI: 10.1016/j.addbeh.2016.03.022

Ritchwood, T.D., Ford, H., DeCoster, J., Sutton,M. \& Lochman, J.E. (2015). Risky sexual behaviour and substance use among adolescents: a meta-analysis. Children and Youth Services Review, 52, 74 - 88. DOI: 10.1016/j.childyouth.2015.03.005 
Sneddon, I. \& Kremer, J. (1992). Sex behaviour and attitudes of university students in Northern Ireland. Archives of Sexual Behaviour, 21(3), 25 - 312.

Doi:10.1007/BF01542998

van Nieuwenhuijzen, M, Junger, M, Klein Velderman, M et al. (2009). Clustering of health compromising behavior and delinquency in adolescents and adults in the Dutch population. Preventive Medicine, 48, 572 - 578. DOI:

10.1016/j.ypmed.2009.04.008

WHO (2014). Global status report on alcohol and health 2014. Switzerland: WHO.

Young, H., Burke, L. \& Nic Gabhainn, S. (201). Sexual intercourse, age of initiation and contraception among adolescents in Ireland: findings from the Health Behaviour in School-aged Children (HBSC) Ireland study. BMC Public Health, 18, 362. DOI: $10.1156 / \mathrm{s} 12889-018-5217-\mathrm{z}$

Weis JA, Jampol ML, Lievano, JA et al. (2008) Normalizing risky sexual behaviors: a grounded theory study. Pediatric Nursing, 34(2), 163 - 169.

WHO (2018). Health Topics: Adolescent Health. World Health Organisation. Retrieved July 26, 2018 from http://www.who.int/topics/adolescent health/en/ 
Table 1:

Prevalence of individual behaviours for both samples

Scotland Northern Ireland

$\%_{\text {weighted }} \mathrm{N}_{\text {unweighted }} \%_{\text {weighted }} \mathrm{N}_{\text {unweighted }} \chi^{2}$

\begin{tabular}{lccccc}
\hline Alcohol & 75.1 & 1828 & 59.0 & 818 & $95.56^{* * *}$ \\
Cigarettes & 27.5 & 640 & 23.8 & 328 & 2.70 \\
Sexual & 25.0 & 624 & 9.9 & 136 & $135.42^{* * *}$ \\
Intercourse & & & & \\
Cannabis & 17.2 & 380 & 9.8 & 135 & $25.06^{* * *}$ \\
& & & & \\
\hline Note: Scotland $\mathrm{N}=2489$, Northern Ireland $\mathrm{N}=1405 ;{ }^{* * *}=\mathrm{p}<0.001$
\end{tabular}

Table 2:

Proportions reporting multiple behaviours

\begin{tabular}{lll} 
& Scotland & Northern Ireland \\
\hline 0 & 22.4 & 38.6 \\
1 & 40.7 & 35.3 \\
2 & 16.4 & 14.3 \\
3 & 10.6 & 8.5 \\
4 & 9.9 & 3.3
\end{tabular}


Table 3:

Prevalence and O/E ratios for behaviour combinations

Outcome pattern
Scotland

Observed Expected O/E $\quad 95 \% \mathrm{Cl}$
$\%$ $\%$

\begin{tabular}{|c|c|c|c|c|c|c|c|c|}
\hline No outcomes & 22.40 & 11.21 & 2.00 & $1.83-2.16$ & 38.70 & 46.06 & 1.52 & $1.39-1.64$ \\
\hline Alcohol only & 38.60 & 33.81 & 1.14 & $1.07-1.21$ & 33.30 & 28.23 & $\underline{0.91}$ & $\underline{0.83-0.99}$ \\
\hline Cannabis only & 0.10 & 2.33 & 0.05 & $-0.02-0.10$ & 0.00 & 2.37 & a & a \\
\hline Cigarettes and alcohol & 7.10 & 12.83 & $\underline{0.55}$ & $\underline{0.47-0.64}$ & 10.90 & 4.33 & 0.96 & $0.91-1.00$ \\
\hline Cigarettes and cannabis & 0.00 & 0.88 & 0.00 & $-0.05-0.05$ & 0.10 & 0.36 & 0.12 & $-0.10-0.33$ \\
\hline Cigarettes and sex & 0.00 & 0.00 & a & a & 0.00 & 0.00 & a & a \\
\hline
\end{tabular}

Northern Ireland

Observed Expected O/E $\quad 95 \% \mathrm{Cl}$ $\% \quad \%$ 


\begin{tabular}{|c|c|c|c|c|c|c|c|c|}
\hline Cannabis and sex & 0.00 & 0.78 & 0.00 & $-0.06-0.06$ & 0.00 & 0.26 & a & a \\
\hline $\begin{array}{l}\text { Cigarettes, alcohol and } \\
\text { cannabis }\end{array}$ & 5.30 & 2.66 & 1.99 & $1.65-2.33$ & 4.90 & 0.22 & 3.95 & $3.08-4.83$ \\
\hline Cigarettes, alcohol and sex & 4.60 & 12.83 & 0.36 & $\begin{array}{l}-538.54- \\
539.26\end{array}$ & 3.10 & 4.33 & 0.27 & $\begin{array}{l}-54.07- \\
54.62\end{array}$ \\
\hline $\begin{array}{l}\text { Cigarettes, cannabis and } \\
\text { sex }\end{array}$ & 0.10 & 0.29 & $\underline{0.34}$ & $\underline{0.03-0.65}$ & 0.00 & 0.04 & a & a \\
\hline Alcohol, cannabis and sex & 0.60 & 2.34 & $\underline{0.26}$ & $\underline{0.16-0.39}$ & 0.50 & 0.16 & 1.15 & $0.37-1.93$ \\
\hline All four behaviours & 9.90 & 0.89 & 11.15 & $9.75-12.55$ & 3.30 & 0.02 & 24.23 & $\begin{array}{l}17.65- \\
30.80\end{array}$ \\
\hline
\end{tabular}

Notes: a, values cannot be calculated due to an observed prevalence of 0 ; bold text indicates significant clustering above that expected; underlined and italics indicates significant clustering below that expected 
Table 4:

Multiple logistic regression of membership of 4 lifetime behaviour cluster with sociodemographic characteristics

Scotland

OR

$95 \% \mathrm{Cl}$

OR

Gender

Male

Female

1.267

$0.817-1.965 \quad 0.626$

$0.328-1.195$

Age

1.840

$0.984-3.443$

3.164

$1.634-6.127$

Family structure

Both parents

Single parent

1.867

$1.111-3.137 \quad 2.213$

$1.081-4.531$

Step-parent

2.147

$1.187-3.883 \quad 2.450$

$0.825-7.277$

Other

2.658

$0.763-9.261$

3.497

$0.737-16.591$

Multiple Deprivation

Most Deprived

2.699

1.264 - $5.762 \quad 0.560$

$0.196-1.605$

2

2.964

$1.424-6.117$

0.787

$0.312-1.984$

3

1.493

$0.671-3.322$

0.436

$0.155-1.226$ 
$0.111-1.123$

Least deprived

Notes: Significant values in bold 